Paper presented at The $4^{\text {th }}$ International Conference on the Image, Chicago, 24-26 Oct 2013.

Published in The International Journal of the Image Vol. 4 No. 1. 2014 pp77-86

ISSN 2154-8560

\title{
The Gendered Image: Deconstructing Life Drawing
}

\section{Authors}

Amanda Roberts

Howard Riley

\begin{abstract}
This article argues that viewers of artworks in general, and drawings of the female nude in particular, are positioned in terms of their mood and attitude towards the subject-matter of the artwork specifically by the compositional selections of the maker of the artwork, together with the viewer's gender orientation. Two opposing ideological positions concerning the representation of the female nude are discussed, those of the traditionalist Kenneth Clark and, against him, the early feminists, and their differences charted. The article then proposes that these positions are only two of many available, and demonstrates how a constructivist philosophical base informed by deconstruction theory provides a means of analysis - and synthesis - of drawings which reveals alternative modal positionings of the gendered viewer by means of nontraditional compositional choices. The article is illustrated with drawings by the authors and others.
\end{abstract}

\section{Keywords}

Drawing; Systemic-functional Semiotics; Deconstruction theory; Gender.

\section{Gender and Ideology}

From the outset, this article recognises that all critiques of the representation of female nude will be driven by gender issues, from a range of ideological stances. It intends to focus on the influence and intricacies of gender as a positioning factor in the understanding and generation of artworks. An in-depth analysis of what constitutes gender differentiation lies outside the scope of this article, which instead regards gender as a relative ontological attitude within a constructivist philosophical framework. Within this context gendered identity is understood as pluralistic and fragmented and differing in relation to the social, historical or cultural contexts from which it is formed. The distinction between biological sex difference and sociallyformed gender difference is so commonly interlinked in understandings and expectations that it is impossible to refer to one without evoking the other. In effect, the concept of the biologically female cannot be divorced from social constructions 
and expectations of female gender, i.e. the feminine. Equally, the concepts of female and feminine cannot be disassociated from their oppositional binary positions of male and masculine.

Kenneth Clark's (1960) text The Nude comprehensively demonstrates that representations of the Nude in European art are governed by a series of conventions and social expectations. As a result, Clark argues, representations of the Nude need to be considered as a genre of artistic practice, rather than simply subject matter. Clark's text is seminal in articulating and identifying aesthetic assumptions that had developed around representations of the unclothed body. His stance remained dominant until the early 1970s when feminist theory and practice, stemming from the second wave feminist movement challenged Clark's position with an alternative set of assumptions .The essential differences between these two positions may be neatly charted, Figure 1, and extend the previously assumed feminist legacy identified by . Frances Borzello (2012: 55-87) as the representation of idiosyncratic rather than idealised bodies, the issue based self portrait and female points of view into art positioning them within an alternative feminist canon of the female nude.

\section{Conventions of Representation of the Nude}

\begin{tabular}{|l|l|}
\hline The conventions of the nude & $\begin{array}{l}\text { Strategies to disrupt the conventions of the } \\
\text { nude }\end{array}$ \\
\hline Male /masculine perspective & Female/female perspective \\
\hline Objective & Subjective \\
\hline Nude(Clark) & Naked \\
\hline Male artist/ Female Model (Clark) & $\begin{array}{l}\text { Female artist/Male model } \\
\text { Female artist/Female model } \\
\text { Male artist/Male model }\end{array}$ \\
\hline Female form idealised (Clark) & $\begin{array}{l}\text { Un-idealised, female form, not confirming } \\
\text { To conventional masculine ideal (age, body } \\
\text { shape) } \\
\text { Not conforming to ideals of western art (race) }\end{array}$ \\
\hline
\end{tabular}




\begin{tabular}{|c|c|}
\hline Lack of individuality (Clark, Berger ) & $\begin{array}{l}\text { Nude as portrait or explicitly referencing } \\
\text { an individual's body/face }\end{array}$ \\
\hline $\begin{array}{l}\text { Flowing curves that compositionally } \\
\text { assist the eye in moving over the body. } \\
\text { (Clark) }\end{array}$ & $\begin{array}{l}\text { Compositional strategies that disrupt the viewers } \\
\text { uninterrupted gaze. Fragmentation, jarring or } \\
\text { geometrical rather than curved compositional } \\
\text { structure. }\end{array}$ \\
\hline $\begin{array}{l}\text { Implied sexuality } \\
\text { (Clark) }\end{array}$ & Explicit sexuality/no sexuality \\
\hline $\begin{array}{l}\text { Pleasant to look at } \\
\text { (Clark) }\end{array}$ & $\begin{array}{l}\text { Unpleasant or uncomfortable to look at. } \\
\text { The use of the abject. }\end{array}$ \\
\hline Unaccountable gaze & $\begin{array}{l}\text { Accountable gaze. } \\
\text { Acknowledgement of the viewer's gaze within } \\
\text { the image. E.g. represented figure making eye- } \\
\text { contact with the viewer }\end{array}$ \\
\hline Looking at 'Other' & Looking at self. Self portraits. \\
\hline Tasteful & Distasteful \\
\hline Emotional detachment of artist/viewer & $\begin{array}{l}\text { Emotional attachment of artist/viewer } \\
\text { Active }\end{array}$ \\
\hline Figurative & Abstraction \\
\hline $\begin{array}{l}\text { 'High Art' painting/drawing } \\
\text { sculpture }\end{array}$ & 'Low Art' craft, textiles, graphics. \\
\hline 1 point perspective system & Alternative projection systems \\
\hline Detached from the real world & Positioned within the real world \\
\hline Socially acceptable & Socially unacceptable \\
\hline Psychoanalytical analysis & Semiotic analysis \\
\hline
\end{tabular}

Figure 1 Nudes Convention Chart

It is generally accepted that the early feminist critique of the traditional

representation of the female nude is a valid critique: it is socially constructed and it is

driven by gender-based issues and, as we shall see, it is one of many possible

positions which does actually reflect the social positioning and gender of one of the authors, Roberts.

We argue that representations of the female nude by female artists can by-pass

restrictions of both traditional and feminist canons of the female nude. Some of these

other positions are discussed in the section Alternative Constructions below. 
The research illustrated in this article is concerned with renegotiating the restrictive nature of the feminist canon of the female nude that emerged from early feminist theory. Both Clark's canon and the feminist alternative are defined by guidelines of acceptability that relate to representations of the female body. We argue both canons are refutable.

Presenting the conventions of representation and interpretation of his time as universal, Clark's text reflects a particularly modernist world view, and was systematically dismantled by the post-modern stance of 1970s feminist theorists who revisited the female nude from a politicised and a specifically gendered perspective. Feminist artists and writers exposed the ideological assumptions underpinning the representation of the female nude within a genre devised and practised by men. Assumptions which reflected a patriarchal social structure, in which the female nude was shown to objectify women covertly as passive sexualised objects presented to a voyeuristic male audience.

Having identified the two most prominent ideological positions in relation to the representation of the female unclothed body, it is time to lay the theoretical foundations for the argument put forward in this article, which is that there are many other alternative positions, as yet unexplored. Such foundations consist of a constructivist philosophical paradigm, neatly explained by Nelson Goodman, and a way of construing alternative meanings that itself is a product of constructivist thinking: the deconstructivist methods developed by Jacques Derrida. Both are adumbrated here:

\section{Goodman and Constructivism}

In the foreword to his book Ways of Worldmaking, Nelson Goodman (1978:x) explained his constructivist position as...

...belonging in that mainstream of modern philosophy that began when Kant exchanged the structure of the world for the structure of the mind, continued when C.I. Lewis exchanged 
the structure of the mind for the structure of concepts, and that now proceeds to exchange the structure of concepts for the structure of the several symbol systems of the sciences, philosophy, the arts, perception, and everyday discourse. The movement is from unique truth and a world fixed and found, to a diversity of right and even conflicting versions or worlds in the making.

Such a clear provenance of the constructivist position allows us to recognise that all the cultural artefacts we produce through what Goodman has identified as ways of worldmaking are the products of particular philosophical positions, each position defined by the three parameters of ontology, epistemology and methodology. It may be useful to chart those alternative philosophical bases and their defining parameters, specifically for the analysis of drawing:

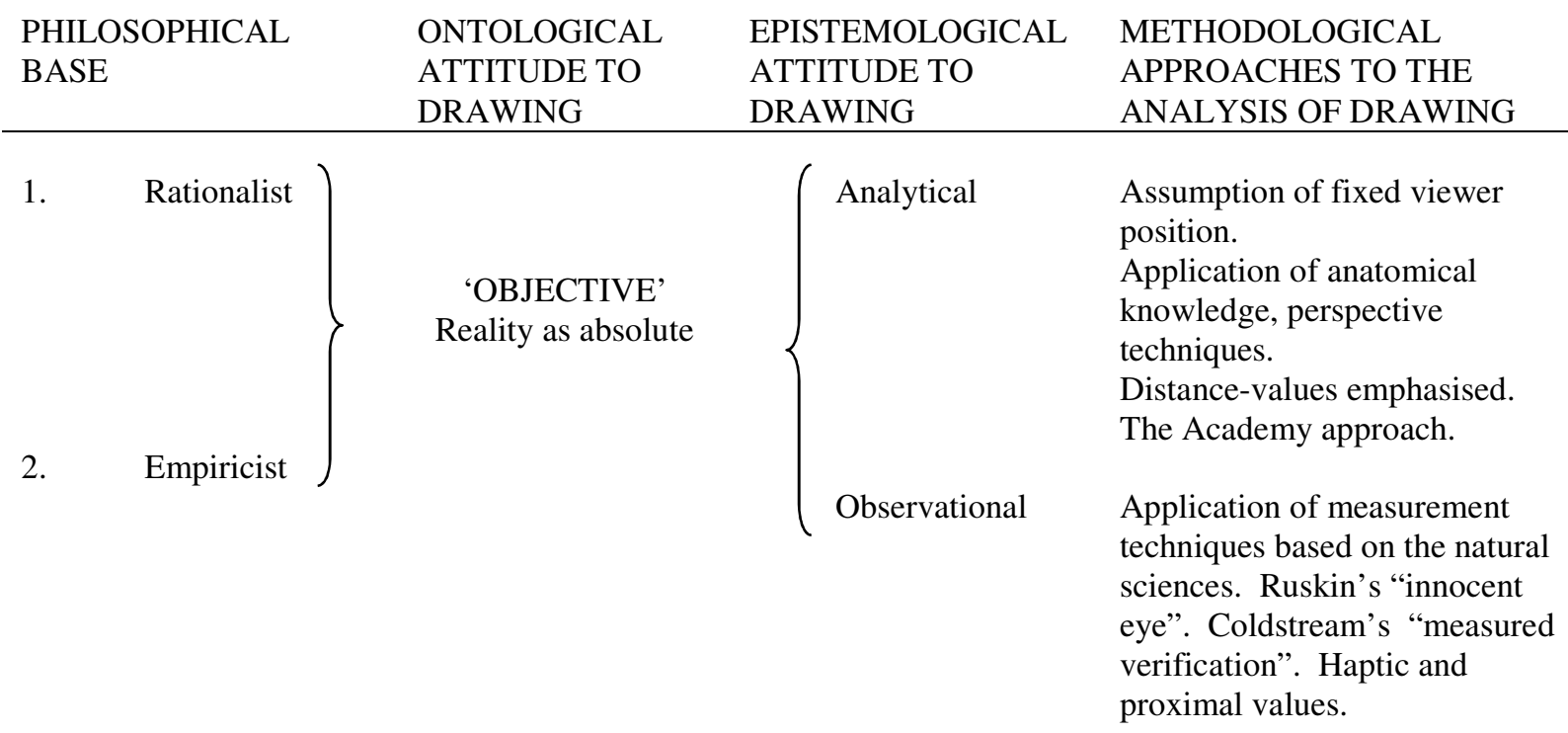

$\begin{array}{ll}\text { 3. Pragmaticist } & \text { 'SUBJECTIVE' Psychological } \\ & \text { Reality as an } \\ & \text { individual } \\ & \text { experience }\end{array}$

\begin{tabular}{|c|c|c|c|}
\hline Constructivist & $\begin{array}{l}\text { RELATIVIST } \\
\text { Realities recognised } \\
\text { as social } \\
\text { constructions, } \\
\text { including the above } \\
\text { categories. }\end{array}$ & Semiological & $\begin{array}{l}\text { Cross-cultural visual studies. } \\
\text { Explicit experimentation with } \\
\text { both viewer-centred and object- } \\
\text { centred representations. } \\
\text { Ecological relationships. Distal, } \\
\text { haptic and proximal values. }\end{array}$ \\
\hline
\end{tabular}
Exploration of emotional responses. Emphasises the 'individual eye'. Distortion of drawn elements, to induce disturbance of emotional response (Kandinsky and Itten)


The chart (Figure 2) summarises the philosophical bases for the analysis (and the production) of drawing discussed in this article. It helps clarify the common terms 'objective' and 'subjective', which will become useful when we analyse the various attitudes adopted to drawings of the female nude (and the oppositional positioning of these attitudes, for example, male/objective, female/subjective) and illustrates the correlations between philosophical bases, their ontological and epistemological parameters, and the main methodological approaches to the analysis - the negotiation of meanings - of drawings. It is worth noting that within the binary oppositional system, philosophical bases can themselves be gendered in their categorisation. Subjectivity is more readily associated with the feminine, while objectivity has more masculine connotations.

\section{Derrida and Deconstruction}

One of Ferdinand de Saussure's (1916(1974)) main insights allows us to recognise that the sign is separate from its referent. Jacques Derrida took this further to reveal the innate arbitrariness of the relationship between the signifier (the physical presence of the sign) and the signified (the mental concept triggered by the signifier).

Deconstruction theory is not so much a method of analysing culturally-produced works as a state of mind: the recognition that since any artwork is produced by selecting elements (signs) from their various categories (paradigms) and then combining those elements into syntagms according to the rules, or conventions of the code, then there are alternative selections available in the paradigms that have been deferred. These deferrals float in the background, present but absent. (Such an apparently oxymoronic phrase - foregrounding both terms of an opposition, when under normal circumstances one term is favoured over its opposite - is itself a demonstration of the power of Deconstruction to reveal that which is normally repressed.) 
Derrida's (1967) invented term diffèrance, its sense suspended between the two verbs to differ and to defer, illustrates through its own ambiguity the point of the Deconstructionists: to take apart apparently stable syntagms from which preferred meanings conforming to the dominant ideology are made, in order to reveal the many alternative syntagmatic combinations affording the negotiation of meanings which were otherwise repressed.

There is no signifier that carries meaning which is not shot through with the echoes of other signifiers. For example CAT means what it means because it is not BAT, CAR or COT. These deferred signifiers thrust themselves into our consciousness as soon as we recognise the differential nature of all sign-systems; the meaning attached to any particular sign depends upon its signifier differing from (whilst being associated with) all other signifiers in the paradigm.

Out of this play of signifiers, this spillage of meanings that Roland Barthes (1977: 9) termed jouissance, certain meanings are elevated by the dominant ideology to a privileged position, and these soon assume that status of natural truth. So it is with attitudes to the representation of the female nude, the topic under scrutiny in this article.

The self-contained work that early structuralism recognised as the product of an enclosed system of signs becomes the open-ended, multi-dimensional text of the poststructuralists. All texts - writings, paintings, drawings - become complexities with depths of multiple meanings - one of which may be 'preferred' as being compatible with the dominant ideology (the underlying set of social, political, cultural values), but all of which are potentially available, even though normally deferred, repressed or ignored. To deconstruct authoritative work is to reveal the ambiguities, the inherent 
contradictions, the alternative constructions of meanings that the work purports to deny in favour of its own authority.

To deconstruct a text is to dismantle the syntagm and to re-align each element back within the paradigm from which it was selected. By doing so, the alternative selections and combinations that were deferred, repressed, become available to scrutiny.

In this sense, any drawing may be deconstructed by the inquisitive viewer. Liberated from the naturalised conventions, the viewer is free to play within the drawing, identifying the ideological motives that authorise the preferred reading.

In this way, all authored works, including drawings, are seen to be political, their form produced by conscious or unconscious choices made by the author (artist) according to some dominant ideological position.

This positioning of the form and interpretation of artworks as socially formed and variable can be illustrated by changing expectations and understandings of the representation of the female nude. Representations of the unclothed female body offer detectable links to culturally- and historically-anchored social structures and attitudes.

\section{Alternative Representations of the Female Nude: Alternative Constructions of Meanings}

A number of female artists have produced work that revisited the female nude with the intent of reclaiming the female body in terms of a female perspective. Subsequently criticised for purporting to represent a universal and essentialist interpretation of gender while continuing to facilitate a sexual and objectified response to the bodies represented in their art, feminist artists and theorists grappled with methods of representing the unclothed female body that would disrupt a 
voyeuristic sexual response from viewers whose perceptions had been conditioned by what could be termed the Clarkist Canon:

\section{Case Study: Anna Mendieta}
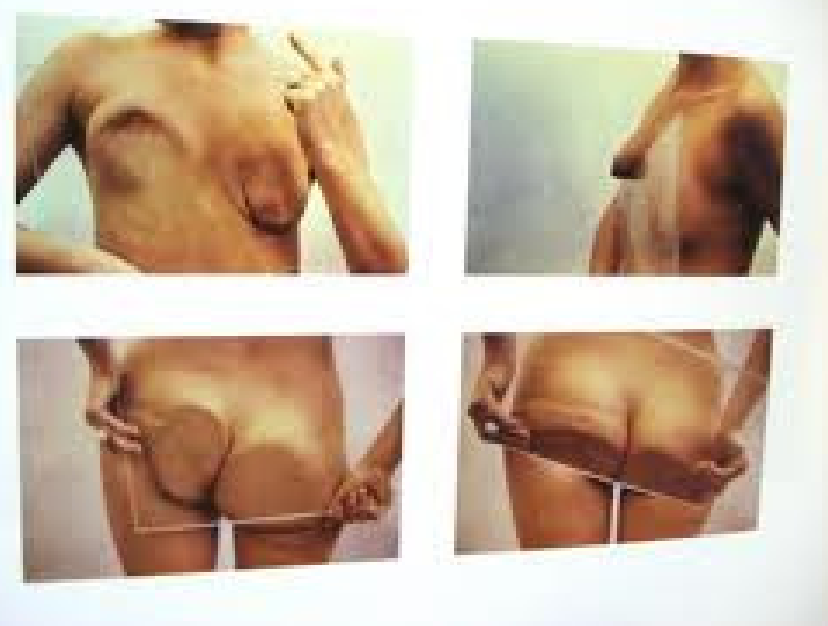

Figure 3 Anna Mendieta; Untitled (Glass on Body Imprints) 1972.

Anna Mendieta's work (Figure 3) is largely compatible with the feminist canon Her works are self portraits, exempting them from potentially voyeuristic or exploitative relationships with their subject and disrupting the potentially voyeuristic gaze with its confrontational and aggressive representations. This strategy gives the represented figure autonomy over the manner of its representation, but, despite the artist's intentions, cannot categorically avoid sexual interpretations of the images by viewers. Mendieta's preference for photography, installation and performance and her presentation of the body in uncomfortable or disturbing contexts, typifies many of the emerging strategies utilised by feminist artists in referencing the female body. Materially and conceptually, many of the feminist approaches to understanding and producing art works pre-empted a wider paradigm shift from modernism to postmodernism.

\section{Case Study: Joan Semmel}




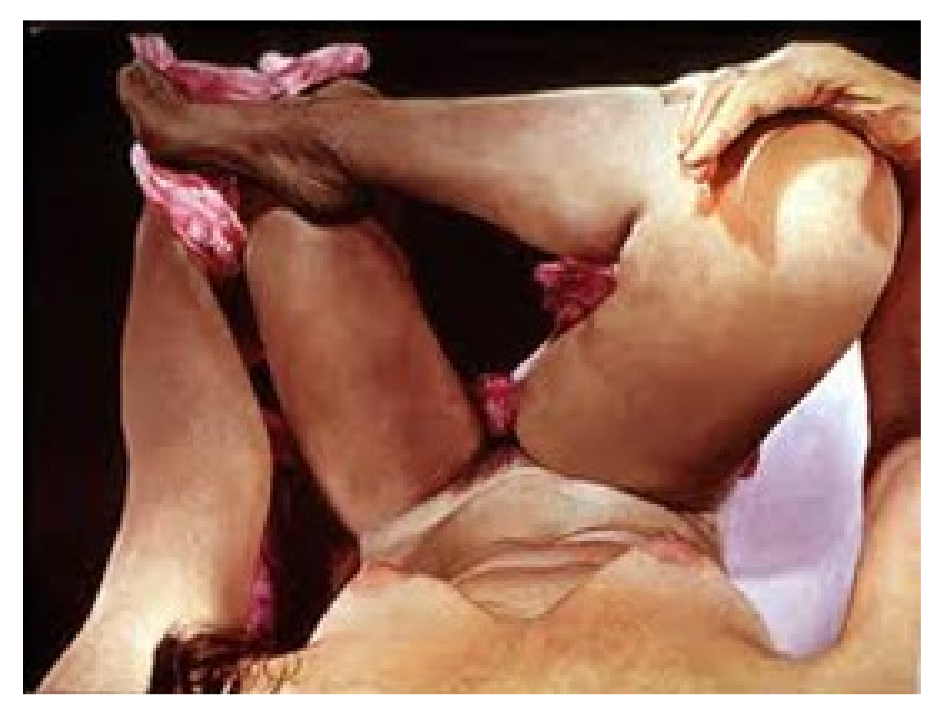

Figure 4 Joan Semmel 1974 Me without Mirrors

Joan Semmel (Figure 4) seeks to evoke empathy within the viewer through a geometric representation of the artist's view of her own body. This can be seen as a pragmaticist strategy where the viewers' objective viewpoint is replaced by the individual eye of the artist, positioned so that they see the represented body as if it were their own. This personalised view encourages an empathetic response in viewers who are afforded the opportunity to share the embodied experience of the represented body. It could be argued that encouraging a sympathetic response through viewpoint alone is too subtle a strategy to disrupt satisfactorily a voyeuristic, sexuallyobjectifying response to the image that continues to display the naked female body as an object for visual contemplation without confrontation or accountability.

This image offers an insight into the potential for the deconstructionist strategy of foregrounding both terms of an opposition. Me without Mirrors references both the Feminist and traditional canons of the female nude, but corresponds to neither. In this image the oppositional distinctions between self and other, emotional attachment and detachment, generic representation and portrait painting all become blurred.

Anna Mendieta and Joan Semmel's art works explicitly foreground the artists' ideological social positioning and directly confronts the viewers' responses to this 
gendered representation. But conflicting responses to these works demonstrate all representations and critiques of the female nude will be ideologically/gender driven.

\section{Case Study: Amanda Roberts}

An analysis of Pippa;Reclining Sprint (Figure 5 ) demonstrates how semiotic analysis, focusing on the deconstructionist technique of revealing both poles of dialectical oppositions, one of which is conventionally foregrounded at the expense of the other, provides a way to unravel and expand meanings inherent in work. The title of the work, Pippa Reclining Sprint, juxtaposes oppositional features integrated into the model's pose and the composition of the image. Reclining nudes are a genre within the conventional canon. Typically, a reclining nude represents the female form lying on her side turned towards the viewer passively displaying her body to the viewer. In Figure 5, Pippa, the model, is reclining on cushions, but her body is represented from the side. The raised knee of her right leg and extended left leg suggest coiled tension, potential movement in a figure that is otherwise relaxed. Within the Nudes Convention Chart (Figure 1), the dialectical opposition between passive (feminine) and active (masculine) has been unravelled resulting in a represented figure that corresponds to neither, but references both. Similarly the image complies neither with Clark's insistence on an anonymous generic representation of the female nude, nor feminism's emphasis on the individual idiosyncratic body. The image undoubtedly contains an element of portraiture; this is referenced in the title which identifies the model as Pippa, and also in the painting of the face which offers a details observational representation of the model. As the viewer's gaze moves away from the head, the painting becomes less specific and more generalised; the brush strokes become larger, broad and loose; the outlines of the legs are generalised and sweeping; and the form of the body more sculptural and generic. 
These discernible combinations of opposites in representation are a reflection of the working method used to produce the painting.

The scale of the work positions it as monumental while the orientations of the viewer to the drawings and the artist to the model combined with the variable perspective system introduces the opposite: the potential of intimacy. Connotations of intimacy are continued in the intense observational focus on the represented woman's face, and also through the gestural quality of the mark making which embodies the physicality of the artist evidencing the weight and rate of movement of the artist's hand or body on the paper. Large sweeping lines reflect the scale and monumental presence of the drawings, heavy, denser, more overworked areas, most consistent in the representation of the face, suggest areas of more intimate concentration and focus.

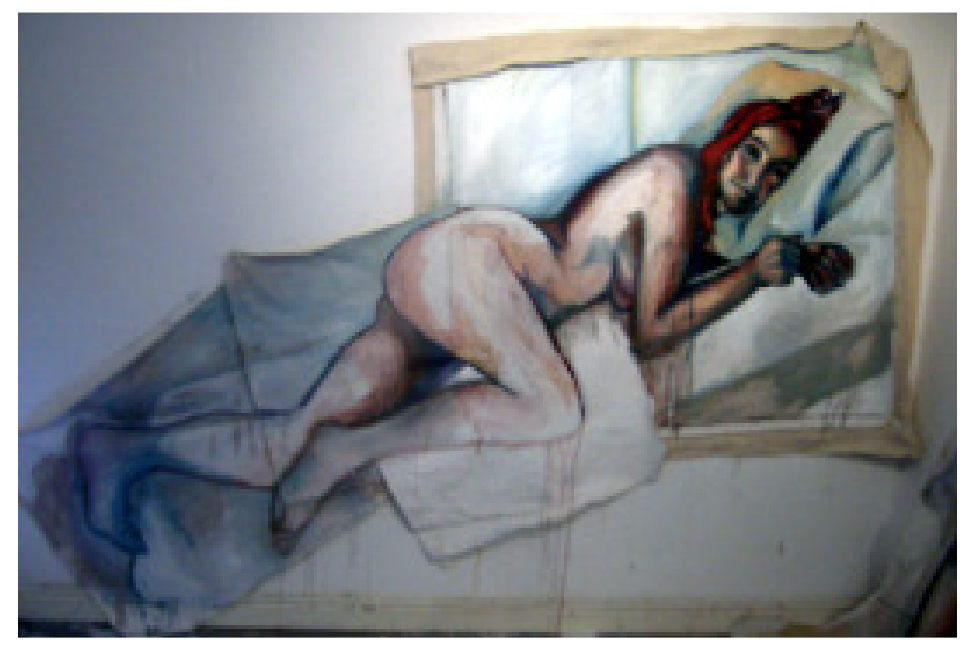

Figure 5 Amanda Roberts Pippa: Reclining Sprint

Any of the oppositions identified in the Nudes Convention Chart (Figure 1) can be taken as a starting point for generating meanings, this article contextualises its analysis within the oppositional stance of gendered conventions of the nude/strategies to disrupt the conventions of the nude. If the traditionally accepted reading of the 
nude is that it represents a fundamentally masculine perspective, then the representation of a female model by a female artist suggests an oppositional stance. That a female artist will represent a female perspective through gender as an embodied viewpoint is inevitable. There is no guarantee that this female perspective is tangible in the resultant artwork as a female artist can undoubtedly produce work that complies with conventions designed to reflect a male formulated canon or ideal. The inclusion or omission of socially specific, visual indicators of gender, that can comply with or disrupt established conventions, reflects a series of conscious or unconscious choices on the part of the artist.

The viewer's recognition and association of these indicators of gender are tangible, but mutable and culturally dependent.

\section{Conclusion}

This article has shown how a deconstructionist semiotic analysis allows us to recognise the rules, conventions and the ideological values that creates them. With such insight, we can choose, both as artists and as critics, what our positioning is and understand the implications of what we represent. Within this model, visual representation and visual analysis are understood within specific social, cultural, historical and gendered contexts. These understandings facilitate informed choices that can comply with, challenge or deconstruct inherent expectations and assumptions and in doing so extend the boundaries of established conventions through both critical theory and visual art practice.

\section{References}

BARTHES, R. 1977 Image, Music, Text. London: Fontana.

BORZELLO, F. 2012 The Naked Nude. London: Thames and Hudson. 
BROUDE, N. and GARRARD, M. D. 1982 Feminism and Art History: Questioning the Litany. New York: Harper \& Row.

CLARK, K. 1985. The Nude : A Study of Ideal Art. Harmondsworth : Penguin.

DERRIDA, J. 1967 Of Grammatology. Baltimore, MD: John Hopkins University Press.

GOODMAN, N. 1978 Ways of Worldmaking, Indianapolis: Hackett.

SAUSSURE, F. de. 1916(1974) Course in General Linguistics, Glasgow:

Fontana/Collins. 